\title{
Social Networking and Secondary Schools: Evaluation of the Efforts of the KP
}

\author{
Government \\ * Dr. Waqar UN Nisa Faizi, Assistant Professor (Corresponding Author) \\ ** Dr. Anila Fatima Shakil, Associate Professor \\ *** Dr. Rabia Abdul Karim, Associate Professor
}

\begin{abstract}
The Pakistani education system is facing deep-rooted problems for a very long period. Though some policies are devised to enhance the education system, especially the secondary education system in Pakistan. This research has therefore aimed at exploring the incorporation of social networking in secondary education while considering the efforts of the KP Government to reform the educational system. From its results, it is analyzed that the KP government has proposed effective approaches, yet many efforts need to be taken to properly accept and integrate social networking in making the education system more effective.
\end{abstract}

Keywords: Social Networking, Secondary Schools, Evaluation, Efforts

\section{Introduction}

The education system in Pakistan has been facing problems from a very long period in terms of quality, accessibility, and equal opportunities (Farid et al. 2015). It is also observed that secondary education is more severely facing these problems as compared to primary level education. Though it is commonly noticed in all over Pakistan that recent trends are encouraging such as an expansion of higher education opportunities, the rapid increase in the private schooling system, and an increase in budget for educational opportunities yet the dilemma of systemic reforms is elusive stubbornly. Successive governments remain unable to provide an educational system that greatly enhances the capabilities of students to cope with modern transformations which is why there are severe barriers for the economic and social development of Pakistan. However, the inabilities of government to take needed actions now could have increased the problems since there is a burgeoning youth population and an increase in the competition among developing counties. Thus, there was a need for devotion, innovation, and more focused attention to education.

In today's world's community of students is drastically influenced by social networks and social media because such technology is increasingly becoming the part of life for everyone (Sánchez, Cortijo, \& Javed, 2014). It cannot be deniable that innovation and advancements in every field are taking place rapidly thus information technologies are also getting innovated. The prime example of innovation in IT includes several social networking sites such as LinkedIn, WhatsApp, Facebook, or Twitter. These platforms offer contemporary patterns of interaction and communication. Certainly, the users of social networking sites can read or find online information mostly in the form of selfpublished posts wherein users do not need physical interaction. This study has examined how well the idea of integrating social networking and secondary education in the context of Pakistan is effectual and analyzing the efforts of the KP Government towards social networking and secondary schools. According to the definition, social networking is the computer-mediated technology that facilitates the sharing and growth of the awareness, ideas, information, interest, and many other aspects that are linked to the expression using virtual communities. There are many social networking sites introduced some of them even associated with their messengers. A research study has defined that social network is represented by a social structure which exhibits various settings of social actors (communities, organizations, and people) and involves communication and social interaction of these actors (Milroy \& Llamas, 2013). It is quite arguable whether innovation in technologies has given positive changes

\footnotetext{
* Department of Education, Islamia College Peshawar Email: faizi@icp.edu.pk

** Department of Education, Jinnah University for Women Karachi

***_Department of Education, Jinnah University for Women Karachi
} 
in the world or negative changes in the world. Though it is agreed by everyone that the effect of social media and social networking sites has had a momentous influence on students and their learning. Under this consideration, the effort of the KP Government is evaluated for the integration of social networking in secondary schools.

\section{Research Question}

The main research questions of this study are:

$>\quad$ What are the efforts of the KP Government towards enhancing the education system?

$>\quad$ What is the impact of integrating social networking with secondary schools?

The main research question was: What perceptions do the teachers hold regarding the integration of social networking in secondary schools?

\section{Objectives of the Study}

This research aims to evaluate the role of the KP government in enhancing the educational ratio of the province. In this regard, the objectives of the research study are:

$>\quad$ To analyze the issues of the education system especially in KPK that are resolved by its government

$>\quad$ To gain insight into the milieu of Pakistan in terms of education

\section{Significance of the Study}

According to the observations, it is discovered that using social networking sited in the school of Pakistan is not encouraged in the setting of classrooms. Furthermore, teachers also feel uncertain for the integration of social forums in lesson plans and curriculum. Therefore, this study is aimed at elaborating on how social networking can enhance their learning and education system as taking the case of the KP Government. The core significance of this study lies in providing an understanding of how authorized bodies can apply social networking in secondary school classrooms along with considering the measures that should be implemented while using social networking platforms for learning.

\section{Literature Review}

For a very long time, social media is now ruling on the Pakistani society as it has gained extreme popularity within the past five to six years (Shabir et al., 2014; Arif, Aslam, \& Ali, 2016). According to the study of Chen \& Bryer, (2012) social networking sites have been experiencing an upsurge in terms of their users as LinkedIn has reached up to one hundred million members, Facebook has increased by 750 million users since 2012, twitter reached up to 177 million tweets, and 3 billion active users on YouTube every day. In the research study of Mao, (2014), it is found that students of college and schools are most of the time exposed to these forums using the means of laptops, personal computers, or cellular devices which stimulate them to continuously engage with online sharing of content, networking, and blogging. Since social networking forums are now deeply rooted in our lives, using it as the approach to enhance learning and education systems will provide ultimate benefits.

\section{Social Networking Sites in Lives of Students}

The role played by social media in the lives of students is very significant, either on an academic level or individual level. Therefore, educationists are now looking towards ways that can make full use of social networking to enhance the learning of students and help them grow intellectually. According to Acedo \& Huges, (2014) curriculum should be designed in a way that incorporates social forums to increase the learning of students using different ways. While some of the research studies (such as Porter et al., 2014) have defined that educational institutes are reluctant towards the adoption of technological resources in an educational setting. In the context of Pakistan, this reluctance might be based upon inadequate information or knowledge among teachers regarding how social networking sites can be used to enhance student's participation. On the contrary, using social networking sites without appropriate knowledge and expertise can become severely terrible (Gibson et al., 2015). Though creating forums that motivate students to take part actively in discussions related to lessons may intrinsically involve students towards learning while using social networking sites. There is indeed no way to return from the life that is dominated by social networking sites for every living being including students of secondary education. As a result, teachers are required to have an adequate understanding of how they can apply social networking forums on their lesson plans and curriculum to make the education system more effective and more interactive. 


\section{Milieu of Pakistan}

In Pakistan, people are not aware of utilizing social networks which is why this concept is still in its developing stages. As per the BBC, only 67 percent of the young adults in Pakistan were exposed to Facebook in 2012 (BBC, 2012). Though the ratio has increased significantly now which is why some of the studies are specifically intended to analyze its effect in Pakistan (Arif, Aslam, \& Ali, 2016). According to the study of Tariq et al. (2012), it was shown that social networking sites such as Twitter, LinkedIn, or Facebook harm the education as well as on the lives of students. On the other hand, studies like Lu \& Churchill, (2014) have shown that social media can be used as an admirable source that fosters collaborative learning among students. In KPK, some of the schools are thus provided with a technological gadget such as e-books and tablets that are becoming increasingly popular. However, besides KPK, there is no other province in Pakistan that has introduced technology and the use of social sites in the context of secondary education (Mustafa, 2012). Universities have been mainstreaming in terms of using social networking for education, however, the KPK government was the pioneer in terms of introducing in the secondary level education system. Many of the schools across the globe have been using social networking for conducting interactive sessions for students (Roohi \& Ahmad, 2016; Mahmood et al., 2018).

\section{Social Networking standard and implementation in Secondary Schools}

In the research of Anderson, (2014) it was stated that there is a need to bank on school management for educational consultants and instructional technologists to achieve trustworthy strategies for social media implementation. In this regard, the basic task is to form teams in secondary school consist of educators that could and could not use social networking resources in the context of the classroom for encouraging participation. Teams should not be limited to teachers only, but it should also consist of heads, lead teachers, coordinators, and all other staff to achieve ideal results. In the second step, research should be performed wherein teams should initiate their working through analyzing the policies of schools that are already in place. With the help of this step; learning opportunities can be crystallized, however, the team is also needed to observe and scrutinize the guidelines that can be used for incorporating social networking within a secondary school setting (Anderson, 2014). In the third step, the process of collecting and drafting the collected data is performed. In this step, the agreement of all team members on the final draft is important and the team should properly document the obtained information. In this phase of taking measures to implement social networking in the educational setting, all heads, teachers, and staff contribute and give their feedbacks (Anderson, 2014). In the last step, agreed guidelines should be implemented within the premises of the school. In this regard, every teacher has an essential duty of educating and informing their students, guardians, parents, or other related entities about the implementation of social networking policies. In this way, the implementation of social networking sites in the setting of secondary education can be done properly and systematically which provides fruitful results.

Some studies conducted on an international level suggested favour in terms of integrating social networking in secondary education. However, in the context of Pakistan, it is still considered as an enormous problem when it comes to integrating social media and secondary education. Studies have also shown that teachers in Pakistan are also not in favour of using social media forums for education and incorporate such practices in curriculum or daily lessons. The question is raised after this review of why Pakistan is (mostly) facing this issue whereas all other countries across the world are practicing it without any hesitation. As per the analysis, the answer to this question that usually it is noticed in the framework of Pakistan, and specifically in the scenario of academics, use and implementation of social media forums lacks the aspect of guidance and supervision. Though KPK Government has initiated the step of implementing social networking in the secondary education context yet it has not gained results as per the expectations.

\section{Methodology}

This section of the study discusses the key strategies and basic design that underlies this research. The research paper has shed light on the importance of the methodology of the research by stating that it has shown the working principle of study and thus gives an understanding regarding the base of the paper (Bell, Bryman, \& Harley, 2018). In this way, this section has provided information regarding data collection, data analysis, research instrument, and ethical consideration of the research along with defining its validity and reliability. 


\section{Research Design and Approach}

The research approach that is undertaken in this study is a mixed-method approach which includes quantitative and qualitative designs. In terms of qualitative design, secondary data has been used; however, in terms of quantitative design, primary data has been used. Therefore, this study also contains the analysis of secondary data as well as primary data. Secondary data is obtained employing past research papers and news articles whereas primary data is acquired by the help of a questionnaire on the topic of social networking and secondary schools - evaluation of the effort of the KP Government. Using mixed methods (literature and survey questionnaire) not only delivered a strong approach for data collection but it has also increased the strength of this study (Bryman, 2016).

\section{Data Collection}

The process of data collection in this research is based on two approaches. For collecting primary data through a survey, the questionnaire has been distributed among participants. The population of KPK was the participant for this study so that field and valid data can be obtained. For the secondary data collection using literature, past research papers were gathered with the help of different keywords' combinations. From sources such as Google Scholar, Jstor, and other official sites of the KPK government along with reliable news platforms such as Tribune and Economist, data for literature has been collected. Therefore, this study has collected its data with the help of two different methods including literature and survey questionnaire.

\section{Data Analysis}

The process of data analysis in this research paper is based on SPSS (Statistical Package for the Social Sciences) analysis on the data that is acquired utilizing a survey questionnaire. The nature of data is based on the Likert Scale which is one of the effective tools for achieving responses for close-ended questions. The numerical score has been used to provide the answer to the survey question. Primary Data analysis has also been presented by using tables, charts, and figures. On the other hand, the analysis of secondary data is done utilizing a constant comparative approach which entails the systematic application of logic into the discussion that is received from the literature.

\section{Research Instrument}

The research instrument for secondary data is past research papers and publications whereas the research instrument for primary data is a questionnaire that was comprised of 5 - Likert scale. The secondary research instrument has entailed over 15 research papers. On the other hand, the primary research instrument has entailed 5 research questions that were asked by the participants living in the province of KPK.

\section{Ethical Consideration, Reliability, and Validity of the Research}

To maintain the ethics of this research, all the information has been cited appropriately as well as the consent of the participant has also been acquired. In terms of research's reliability, the results are constructed using authentic sources of primary and secondary data. Similarly, the validity of the research has also been maintained by gathering the latest information. Thus, no research paper or new article has been included in the study that was published before 2012 .

\section{Results and Findings}

This section in this study contains results and findings of primary data and secondary data that are then discussed to co-relate with each other to achieve the aims and objectives of the research and to answer the question of this research as mentioned above. Primary results are obtained utilizing analysis via SPSS.

\section{Primary Results}

FREQUENCIES VARIABLES $=\mathrm{q} 1 \mathrm{q} 2 \mathrm{q} 3 \mathrm{q} 4 \mathrm{q} 5$

/STATISTICS=STDDEV MEAN MEDIAN MODE

/ORDER=ANALYSIS.

\section{Frequencies}

Table 1: Frequencies and Notes

Notes

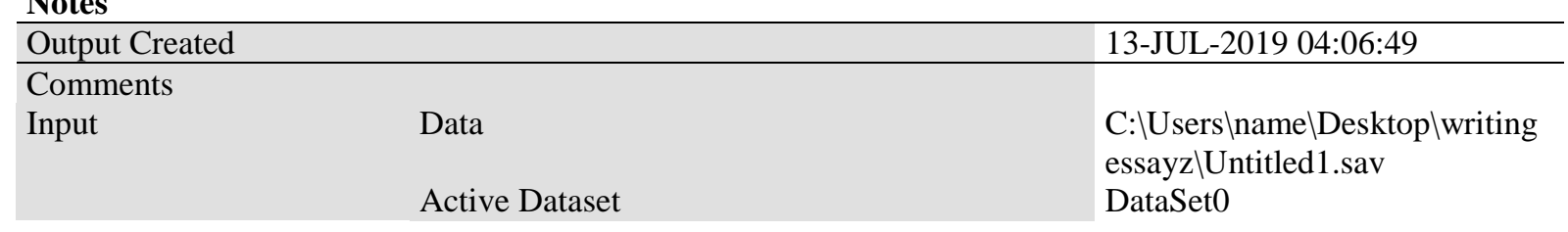




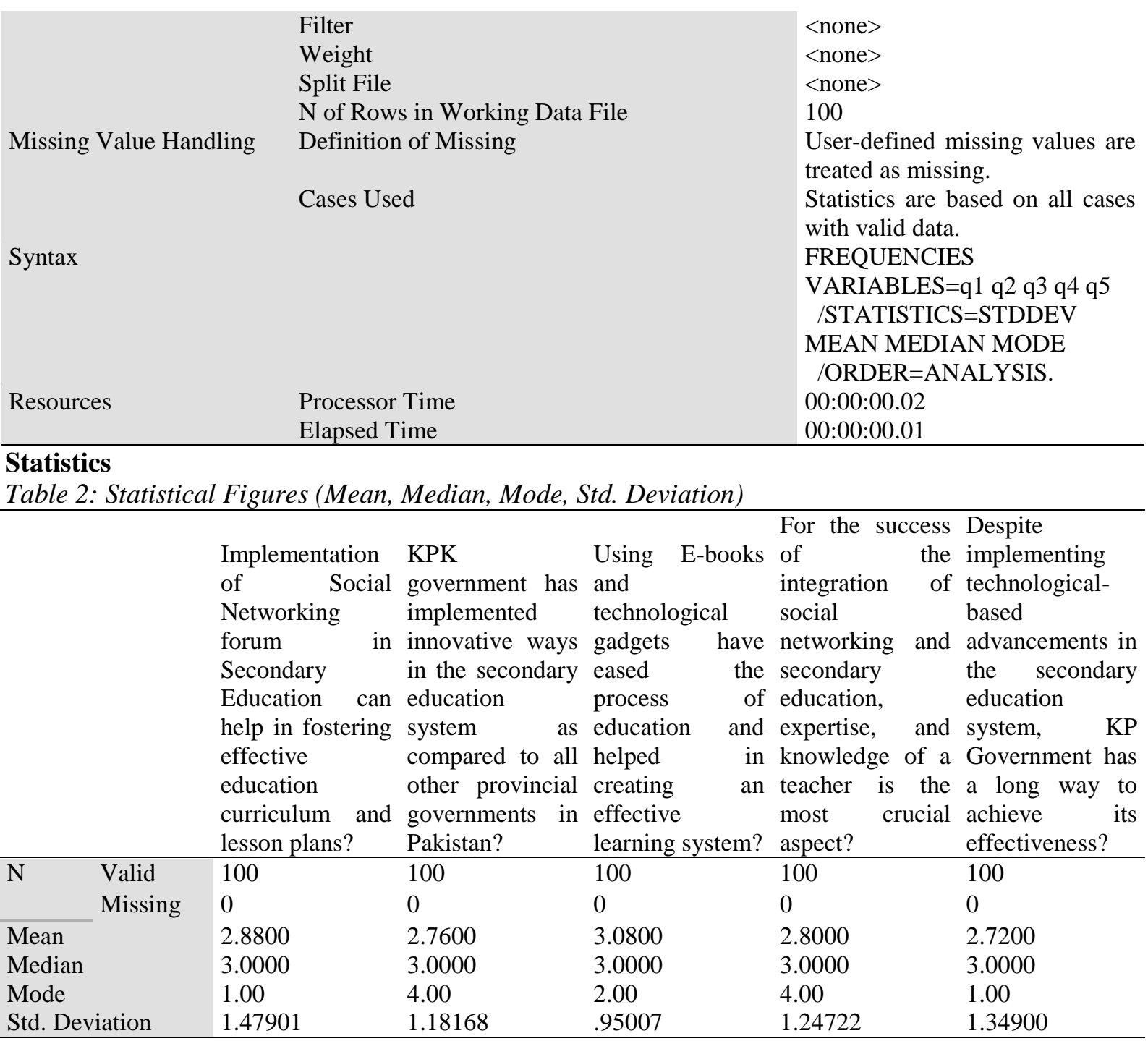

Frequency Tables

Question No. 1

Table 3: Responses on Question No. 1

Implementation of Social Networking forum in Secondary Education can help in fostering effective education curriculum and lesson plans?

\begin{tabular}{llllll}
\hline & & & & Cumulative \\
& & Frequency & Percent & Valid Percent & Percent \\
\hline Valid & Strongly Agree & 27 & 27.0 & 27.0 & 27.0 \\
& Agree & 17 & 17.0 & 17.0 & 44.0 \\
& Neutral & 14 & 14.0 & 14.0 & 58.0 \\
& Disagree & 25 & 25.0 & 25.0 & 83.0 \\
& Strongly Disagree & 17 & 17.0 & 17.0 & 100.0 \\
& Total & 100 & 100.0 & 100.0 & \\
\hline
\end{tabular}

In this statement, the respondents are asked about the use of various techniques of learning which can be used by the learner and instructor as well to increase their learning abilities up to a great extent. The extent of social networking towards the learning abilities of the learner is being asked in this statement. Social networking refers to the adoption and use of specific websites and applications through which individuals can increase their interaction and communication abilities with each other. Through this, the extent of discussion and brainstorming goes up along with improvement in confidence level and interaction level hold by individuals. This increases the learning skills of the individuals. For this, $27 \%$ and $17 \%$ of respondent's state strongly agree and agree to respond to this statement. Besides this, $14 \%$ of respondents state Neutral responses towards this statement. In addition to this, $25 \%$ and $17 \%$ of respondent's state disagree and strongly disagree response towards 
this statement. Overall, most of the respondents believe that the use of social networking holds enough potential to enhance the learning quality and learning base plans which the learners can adopt and undertake as well during secondary education level. The social networking base application and website bring effective improvement towards the available learning plans.

Question No. 2

Table 4: Responses on Question No. 2

KPK government has implemented innovative ways in the secondary education system as compared to all other provincial governments in Pakistan?

\begin{tabular}{llllll}
\hline & & & & Cumulative \\
& & Frequency & Percent & Valid Percent & Percent \\
\hline Valid & Strongly Agree & 18 & 18.0 & 18.0 & 18.0 \\
& Agree & 26 & 26.0 & 26.0 & 44.0 \\
& Neutral & 22 & 22.0 & 22.0 & 66.0 \\
& Disagree & 30 & 30.0 & 30.0 & 96.0 \\
& Strongly Disagree & 4 & 4.0 & 4.0 & 100.0 \\
& Total & 100 & 100.0 & 100.0 & \\
\hline
\end{tabular}

In this statement, the respondents are asked about the extent of effective and quality-based initiatives adopted and implemented by the local KPK government to increase the quality of learning programs available for learning at the secondary education level. For this statement, $18 \%$ and $26 \%$ of respondents state a Stringy agree and agree response, respectively. Besides this, $22 \%$ of respondents state a Neutral response towards this. In addition to this, $30 \%$ and $4 \%$ of respondents state Disagree and strongly disagree response towards this statement. It reflects that most of the respondents believe that efforts and investment made by the KPK government to improve the learning program and its quality at the secondary education school level is quite impressive and value-based as well in contrast to the efforts made by the provincial government of the other provinces and central government as well on the federal level.

Question No. 3

Table 5: Responses on Question No. 3

Using E-books and technological gadgets have eased the process of education and helped in creating an effective learning system?

\begin{tabular}{llllll}
\hline & & & & \multicolumn{2}{c}{ Cumulative } \\
& & Frequency & Percent & Valid Percent & Percent \\
\hline Valid & Agree & 34 & 34.0 & 34.0 & 34.0 \\
& Neutral & 31 & 31.0 & 31.0 & 65.0 \\
& Disagree & 28 & 28.0 & 28.0 & 93.0 \\
& Strongly Disagree & 7 & 7.0 & 7.0 & 100.0 \\
& Total & 100 & 100.0 & 100.0 & \\
\hline
\end{tabular}

In this statement, the respondents are asked about the trend of using e-books and other IT base learning gadgets and techniques which can be used to improve the learning process among the learners and to increase the efficiency of the existing learning system as well. The use of modern learning technologies brings high-quality base results towards the learning system and learning quality hold by learners. For this statement, $34 \%$ and $31 \%$ of respondents state agree and neutral response towards this statement. Besides this, $28 \%$ and $7 \%$ of respondent's state disagree and strongly disagree response towards this statement. Most of the respondents hold a negative response towards the use of e-book and other electronic means of learning and education as well. Most of the respondents hold a disagree response towards this that e-books and other learning gadgets bring no effects towards the learning system and its effectiveness as well.

Question No. 4

Table 6: Responses on Question No. 4

For the success of the integration of social networking and secondary education, expertise, and knowledge of a teacher is the most crucial aspect?

\begin{tabular}{llllll}
\hline & & & & Cumulative \\
& & Frequency & Percent & Valid Percent & Percent \\
\hline Valid & Strongly Agree & 23 & 23.0 & 23.0 & 23.0 \\
& Agree & 17 & 17.0 & 17.0 & 40.0 \\
& Neutral & 20 & 20.0 & 20.0 & 60.0 \\
& Disagree & 37 & 37.0 & 37.0 & 97.0
\end{tabular}




\begin{tabular}{lllll} 
Strongly Disagree & 3 & 3.0 & 3.0 & 100.0 \\
Total & 100 & 100.0 & 100.0 & \\
\hline
\end{tabular}

In this statement, the respondents are asked about the role of teachers regarding increasing the learning trends among students and the trend of using advanced learning materials as well. The respondents are asked about the awareness level holds by the teachers regarding the use of social networking techniques which can be used by the learners and teachers to increase the learning quality and its output level among the students. When teachers are familiar with the use and effects of social networking techniques for learning, they can guide their students effectively in this regard. For this statement, $23 \%$ and $17 \%$ of respondent's state strongly agree and agree to respond to this statement. Besides this, $20 \%$ of respondents state Neutral response towards this. In addition to this, $37 \%$ and 3\% of respondents state Disagree and strongly disagree response towards this statement. Respondents give a combination of responses towards this statement as both $40 \%$ of respondent's state disagree and agree response towards this statement, respectively.

Question No. 5

Table 7: Responses on Question No. 5

Despite implementing technological-based advancements in the secondary education system, KP Government has a long way to achieve its effectiveness?

\begin{tabular}{llllll}
\hline & & & & Cumulative \\
Valid & Frequency & Percent & Valid Percent & Percent \\
\cline { 2 - 5 } & Strongly Agree & 24 & 24.0 & 24.0 & 24.0 \\
& Agree & 23 & 23.0 & 23.0 & 47.0 \\
& Neutral & 23 & 23.0 & 23.0 & 70.0 \\
& Disagree & 17 & 17.0 & 17.0 & 87.0 \\
& Strongly Disagree & 13 & 13.0 & 13.0 & 100.0 \\
& Total & 100 & 100.0 & 100.0 & \\
\hline
\end{tabular}

In this statement, the respondents are asked about the extent of effectiveness regarding the technological advance learning base program. KPK government has implemented several technologically advance learning methods and plans through which the leaning quality at the secondary level of education can improve. Despite the implementation, the desire results can be achieved after some time. For this, $24 \%$ and $23 \%$ of respondents state a strongly agree and agree response towards this statement. Besides this, $23 \%$ of respondents state neutral response for this, and $17 \%$ and $13 \%$ of respondents state Disagree and strongly disagree response towards this statement. Overall, the majority of respondents believe that it will take time to obtain desire results and effectiveness from the advanced technology-based learning program implemented by the KPK government at the secondary level to enhance learning quality among students at the secondary education level.

\section{Discussion}

The results and analysis of primary data have shown a matching pattern as found in the research papers. Though there are so not many studies that have particularly aimed at analyzing the education system in Pakistan and even specifically of Secondary education system. The literature review has suggested that social networking sites have now become an integral part of our lives which is why many of the educationists were looking towards approaches that can make social forums to be used in the learning system. Internationally, many countries are accepting that social networking forums have the potential of increasing the learning and participation of students that can help in overcoming many barriers of education (Gibson et al., 2015). On the other hand, studies that are conducted in the context of the Pakistani education system has depicted a slightly different story. Since the education system of Pakistan is facing issues to enhancing the learning of students. However, news and some research papers have shown that the KPK government is making intense efforts to enhance the learning system and help students become more competitive (Mustafa, 2012; Roohi \& Ahmad, 2016; Mahmood et al., 2018; Dawn, 2018). The results of primary and secondary data have revealed that Social Networking forum in Secondary Education can help in fostering effective education curriculum and lesson plans. However, a significantly large number of the population has also denied that the above fact is based on the reason of lack of expertise. It was also found in news reports, research papers, and primary results that efforts of the KP Government towards enhancing the secondary education system and introducing technological dimensions in education have improved the education reform of KP which is rather improved as compared to other regions of Pakistan. However, social networking in education 
has not yet been incorporated fully into the secondary level education but it can be foreseen soon. The steps for implementation of social networking in education platform has also been elaborated in the literature along with explaining many of its positive and constructive impacts on students' learning but without expertise of educator to implement it effectively; desired results can never be achieved.

\section{Summary}

The results and discussion have shown that integration of social networking forums in the secondary education system of Pakistan fully can help to improve the education reform and the KP government has taken several measures to enhance the educational situation of the region. In this regard, it is analyzed that KP Government has introduced e-books, virtual learning opportunities, and electronic gadgets into the secondary school classroom which is the potential of fostering social networking integration in their lesson plans and curriculum.

\section{Conclusion and Recommendations}

The education system of any country must be strong and effective enough to produce competitive students following the need of the era. In this regard, it is observed that the Pakistani education system lacks the aspect of modifying the curriculum or lesson plan to adjust it with the needs accordingly. It is also observed as one of the most underpinning issues faced by educational reform in Pakistan. For developing an educational system that is competitive enough to cater to the needs of this era, many of the countries are incorporating social networking forum with education considering the high dominance of social media influence in our daily lives. To this end, research papers and opinions of the different people have also shown somewhat favour to combine curriculum with social networking. However, in Pakistan, certain measures should be taken to effectively implement it. Some of the recommendations in this regard are as given below:

$>\quad$ Educate and train teachers to effectively use social networking as part of their lesson plan constructively and effectively.

$>\quad$ Develop effective interacting sessions and provide thought-provoking learning material on social media forums for students to get them engaged with learning and education.

$>\quad$ Mould curriculum and course outlines of secondary education that correspondingly align with social networking requirements.

$>\quad$ Develop vital policies in the schools that are social networking forum friendly and do not obstruct flexibility

\section{References}

Motivate students and parents to positively use social networking to enhance their learning.

Acedo, C., \& Hughes, C. (2014). Principles for learning and competences in the 21 set-century curriculum. Prospects, 44(4), 503-525.

Anderson, S. (2014). How to create social media guidelines for your school. Retrieved from http://www.edutopia.orgpdfs/edutopia-anderson-social-media-guidelines.pdf

Arif, I., Aslam, W., \& Ali, M. (2016). Students' dependence on smartphones and their effect on purchasing behavior. South Asian Journal of Global Business Research, 5(2), 285-302.

Bell, E., Bryman, A., \& Harley, B. (2018). Business research methods. Oxford university press.

Bryman, A. (2016). Social research methods. Oxford university press.

Chen, B., \& Bryer, T. (2012). Investigating instructional strategies for using social media in formal and informal learning. The International Review of Research in Open and Distributed Learning, 13(1), 87-104.

Dawn, (2018). The government aims for a uniform education system under the new policy framework. [Online]. Available at: https://www.dawn.com/news/1447992 [Accessed on $20^{\text {th }}$ June, 2019]

Farid, S., Ahmad, R., Niaz, I. A., Arif, M., Shamshirband, S., \& Khattak, M. D. (2015). Identification and prioritization of critical issues for the promotion of e-learning in Pakistan. Computers in Human Behavior, 51, 161-171.

Gibson, D., Ostashewski, N., Flintoff, K., Grant, S., \& Knight, E. (2015). Digital badges in education. Education and Information Technologies, 20(2), 403-410.

Lu, J., \& Churchill, D. (2014). The effect of social interaction on learning engagement in a social networking environment. Interactive learning environments, 22(4), 401-417. 
Mahmood, A. S., Khattak, N., Haq, N., \& Umair, S. (2018). Technology Integration and Upgradation of Higher Secondary Education: Need of the Hour in Pakistan. In Handbook of Research on Mobile Devices and Smart Gadgets in K-12 Education (pp. 115-133). IGI Global.

Mao, J. (2014). Social media for learning: A mixed-methods study on high school students' technology affordances and perspectives. Computers in Human Behavior, 33, 213-223.

Milroy, L., \& Llamas, C. (2013). Social networks. The handbook of language variation and change, 407-427.

Mustafa, G. (2012). Education policy analysis report of Khyber Pakhtunkhwa. Islamabad: United Nations Educational, Scientific and Cultural Organisation.

Porter, W. W., Graham, C. R., Spring, K. A., \& Welch, K. R. (2014). Blended learning in higher education: Institutional adoption and implementation. Computers \& Education, 75, 185-195.

Roohi, T., \& Ahmad, S. M. (2016). School Heads' Perceptions about Electronic Teaching Technologies in Secondary Schools of Peshawar, Khyber Pakhtunkhwa. FWU Journal of Social Sciences, 10(1), 115.

Sánchez, R. A., Cortijo, V., \& Javed, U. (2014). Students' perceptions of Facebook for academic purposes. Computers \& Education, 70, 138-149.

Shabir, G., Hameed, Y. M. Y., Safdar, G., \& Gilani, S. M. F. S. (2014). The Impact of Social Media on Youth: A Case Study of Bahawalpur City. Asian Journal of Social Sciences \& Humanities, 3(4), 132-151.

Tariq, W., Mehboob, M., Khan, M. A., \& Ullah, F. (2012). The impact of social media and social networks on education and students of Pakistan. International Journal of Computer Science Issues (IJCSI), 9(4), 407. 